\title{
Effects of postweaning rearing conditions on emotionality and social-seeking behavior in the rat ${ }^{\prime}$
}

DEVENDRA SINGH and WILLIAM S. MAKI, JR., North Dakota State University, Fargo, N. D. 58102

Effects of postweaning contact with the mother or like-sexed age-mates were compared with isolation effects on the albino rat. Animals that had experienced some form of social contact weighed more, displayed more social-seeking behavior, and were less emotional than animals reared in isolation. Results were interpreted as showing that behavioral and physiological changes induced by prolonged maternal contact during postweaning life are attributable to the presence of another animal.

Studies in which rats are socially reared, i.e., with either the mother or like-sexed litter-mates, have produced conflicting results. For example, Newton (Bovard \& Newton, 1955) found that rats reared with their mother after weaning were more emotional and weighed less than "gentled" rats; Denenberg \& Grota (1964) reared weaned rats with like-sexed litter-mates or in isolation and found no significant differences between groups in emotionality as measured by defecation and activity. The purpose of the present study was to determine whether postweaning contact with the mother represents a stimulus condition uniquely different from contact with a like-sexed animal of the same age.

\section{Early Experience}

\section{METHOD}

Each of 11 pregnant Holtzman albino rats were housed in white plastic maternity cages partially filled with wood shavings with overhead food hoppers and water bottles. Within $24 \mathrm{~h}$ after birth, each litter was reduced to eight pups; due to subsequent deaths, three litters contained only seven pups. The litters were not otherwise disturbed prior to 21 days after birth, at which time three male pups from each litter were matched by body weight and randomly assigned to one of the postweaning conditions. Each $S$ lived with its mother (Group $\mathrm{M}$ ), another male pup randomly chosen from those remaining after selection of Ss (Group P) or individually (Group 1). Throughout the experimental period, all Ss were housed in $91 / 2 \times 7 \times 7$-in. stainless steel cages with wire mesh fronts and maintained on ad lib food and water. At 51 days of age, cage mates were withdrawn and Ss were weighed. Testing proceeded as follows:

Social Preference

Commencing at 52 days of age all Ss were tested under ad lib food and water conditions for one $10-\mathrm{min}$ period every $24 \mathrm{~h}$ for four days in an apparatus identical in physical dimensions to that reported by Denenberg \& Grota (1964). The apparatus, however, contained identical wire mesh screens located in corners nearest the start chamber in both social and novel chambers. A sliding door separated the start chamber from the social and novel chambers, thus forcing $S$ to choose between social and novel chambers after emerging from from the start chamber. One animal approximately the same age as $S$ randomly drawn from the colony at the beginning of each day served as the social stimulus. Novel stimuli were three small pieces of $1 / 4$-in. plywood cut in random designs, changed each day to insure continuous novelty and attached to the wire mesh by varying lengths of plastic-coated copper wire. Social and novel stimuli were alternated between chambers after each $S$ and werc also alternated between days for each $S$. Time taken by $S$ to emerge from the start chamber (latency) was recorded. as was time spent in the social and novel chambers, defecation and number of alternations between chambers (activity).

Postdeprivation Water Consumption

At 58 days of age all Ss were deprived of water and on the following day testing began. The apparatus was a modified Skinner box $(12 \times 8 \times 10$ in. $)$ with a $100 \mathrm{ml}$ water bottle inserted through the front. The box was placed in a chamber and a buzzer was inserted between the front of the box and the chamber wall. During testing each $S$ was placed in the apparatus for $10 \mathrm{~min}$ every $24 \mathrm{~h}$ for three days. Although all Ss were maintained throughout testing on ad lib food, water was available only during the 10 -min periods on all days of testing. On the third day the buzzer was sounded when $S$ was placed in the apparatus and remained on for the full $10 \mathrm{~min}$. The intervening time between placement in the apparatus and initial drinking was recorded; water consumption and fecal boli were also recorded.

Reaction to Cold Stress

At 68 days of age all Ss were weighed and then subjected to $5 \mathrm{deg} C$ cold stress for $90 \mathrm{~min}$. The animals were then sacrificed and adrenal glands were removed, cleaned and weighed. A spectrophotometric technique reported by Levine, Alpert, \& Lewis (1958) was used to determine the ascorbic acid content of the glands.

\section{Social Preference}

\section{RESULTS AND DISCUSSION}

No differences between groups in latency, activity or defecation were found. An arcsin transformation (Winer, 1962) was applied to the mean percentage of time spent in the social chamber for the four days and these values were analyzed by an analysis of variance. No significant differences between groups were obtained. When Groups $M$ and $P$ were pooled, however, the $S s$ in the combined groups spent significantly more time in the social chamber $(t=2.006$, $p<.05)$ and less time in the novel chamber $(t=2.006$, $p<.05$ ) than Ss in Group I. The fact that Ss that had lived with another animal spent less time in the novel chamber is in keeping with the findings of Denenberg \& Grota (1964).

Post-deprivation Water Consumption

Latency times were subjected to a logarithmic transformation and averaged over the three days of testing. An analysis of variance applied to the data yielded a significant $F$ of 4.613 (df $=2,30 ; p<.05)$. Newman-Keuls tests between means indicated that $S$ s in Group $M$ spent less time in the apparatus prior to drinking than either those in Group P or Group I; these differences were significant beyond the .05 level. Mean times for Groups P and I, however, did not significantly differ. Analyses of defecation scores for the first two days of testing yielded no significant differences. On Day 3, however, Ss in Group I defecated significantly more than Ss inGroups $M$ and $P$ combined $(t=2.046, p<.05)$. No significant differences in water consumption were obtained. In terms of defecation on this test, then, animals that had been exposed in early life to another animal were less emotional than animals reared in isolation. In terms of latency, rats reared with their mothers were least emotional.

Reaction to Cold Stress

No significant differences between groups were found either (a) when adrenal gland weiglits were expressed as functions of body weights, or (b) when ascorbic acid contents were expressed as functions of adrenal weights. As defined by these measures, then, neither postweaning isolation nor social experience appeared to be stressors. Similar findings were 
reported by Krech, Rosenzweig, \& Bennett (1966).

Body Weight Gains

When 51-day weight gains were analyzed by an analysis of variance, no significant differences emerged; as in the case of other measures reported above, differences were obscured by the proximity of Groups $M$ and $P$ means. The mean weight gain for Groups $M$ and $P$ combined was significantly greater ( $t$ $=2.144, \mathrm{p}<.05$ ) than that for Group 1 . Final weight gains (Day 68) did not differ significantly.

In general, the above results suggest that prolonged postweaning contact with the mother does not produce behavioral and physiological changes in the rat markedly different from those produced by contact with a like-sexed animal of similar age. Both of these manipulations tended to increase body weight, increase social-seeking behavior and decrease emotionality when compared to the restriction of postweaning social experience. The above results also suggest that neither postweaning isolation nor social experience act as stressors.

\section{REFERENCES}

DENENBERG, V. H., \& GROTA, L. J. Social-seeking novelty-seeking behavior as a function of differential rearing histories. Journal of Abnormal \& Social Psychology, 1964, 9, 453-456.

BOVARD, E. W., \& NEWTON, D. G. Systematic early handling and prolonged experience with the mother as developmental variables in the male albino rat. In Laboratory animal care. Chicago: Animal Care Panel, Inc., 1955.

KRECH, D., ROSENZWEIG, M. R. \& BENNETT, E. L. Environmental impoverishment, social isolation and changes in brain chemistry and anatomy. Phy siology \& Behavior, 1966, 1, 99-104.

LEVINE, S., ALPERT, M., \& LEWIS, G. W. Differential maturation of an adrenal response to cold stress in rats manipulated in infancy. Journal of Comparative \& Physiological Psychology, 1958, 51, 774-777.

WINER, B. J. Statistical principles in experimental design. New York: McGraw-Hill, 1962.

NOTE

1. A portion of this paper was presented at the annual meeting of the Rocky Mountain Psychological Association, 1968. This research was supported in part by funds from The Graduate School, North Dakota State University. 